\title{
An Effective Electrical Isolation Scheme by Iron Implantation at Different Substrate Temperatures
}

\author{
P. Too*, S. Ahmed, B. J. Sealy, and R. Gwilliam \\ School of Electronics and Physical Sciences, University of Surrey, \\ Guildford, GU2 7XH, United Kingdom.
}

\begin{abstract}
High-energy implantation of iron in n-type doped InP epilayers at different substrate temperatures: $77 \mathrm{~K}$, room temperature (RT), $100^{\circ} \mathrm{C}$ and $200^{\circ} \mathrm{C}$ was investigated to study the electrical isolation of n-type InP. Iron isolation implants were performed at $1 \mathrm{MeV}$ with a fluence of $5 \times 10^{14} / \mathrm{cm}^{2}$. This isolation scheme was chosen to place most of the iron atoms well inside the n-type doped layer. The sheet resistivity $\left(R_{s}\right)$, sheet carrier concentration $\left(n_{s}\right)$ and sheet mobility $(\mu)$ were measured as a function of substrate temperature and post-implantation annealing temperature $\left(100-800^{\circ} \mathrm{C}\right)$. Samples implanted at $77 \mathrm{~K}$, RT and $100^{\circ} \mathrm{C}$ show more or less the same trend of postimplant annealing characteristics. A maximum sheet resistivity of $\sim 1 \times 10^{7} \Omega / \square$ was achieved for samples implanted at $77 \mathrm{~K}$, RT and $100^{\circ} \mathrm{C}$ after annealing at $400^{\circ} \mathrm{C}$. A lower resistivity of $\sim 1 \times 10^{6} \Omega / \square$ was obtained for a $200^{\circ} \mathrm{C}$ implant after annealing at $400^{\circ} \mathrm{C}$. Lower damage accumulation due to enhanced dynamic annealing is observed for the highest implantation temperature. For $200^{\circ} \mathrm{C}$ substrate temperature, annealing above $400^{\circ} \mathrm{C}$ resulted in a gradual decrease in sheet resistivity to a value close to that of the starting material. But this is not the case for the lower substrate temperatures. The sheet resistivity was increased again for $77 \mathrm{~K}$, RT and $100^{\circ} \mathrm{C}$ implant after annealing at $600^{\circ} \mathrm{C}$. We infer that for $77 \mathrm{~K}$, RT and $100^{\circ} \mathrm{C}$ implantation temperatures, the electrical isolation is due to a product of both damage related centers and defects related to the presence of $\mathrm{Fe}$ whereas for $200^{\circ} \mathrm{C}$ substrate temperature, we infer that only damage induced compensation removes the carriers. These results show the importance of iron implants as a device isolation scheme.
\end{abstract}

\section{INTRODUCTION}

Electrical isolation between devices in monolithic integrated circuits is very crucial so as to minimize device/device parasitic effects. This can be achieved either by mesa, dielectric or implantation techniques [1]. Implant isolation is advantageous as the surface planarity is maintained, higher throughput is obtained compared to mesa etch and, in general, less intrusion under the mask edges is observed [2]. Using the ion implantation technique, free carriers are compensated by either irradiation-induced damage or chemically-related deep levels [3]. The choice of the ion species, mass, dose, energy and target temperature depends on the thickness of the layer to be isolated and the required thermal stability of the isolation.
In InP and other In-based compounds, isolation mainly caused by a damage-induced compensation mechanism is not as effective in creating thermally stable high-resistivity regions $[4,5,6]$. In an effort to obtain higher sheet resistivities in n-type InP, we have investigated the implantation of $\mathrm{Fe}$, an impurity which is known to result in high-resistivity InP when used as a dopant during the growth of bulk crystals [7]. Transition elements such as Fe or Co are well known to create deep traps for mobile carriers producing thermally stable semi-insulating InP [8]. The introduction of chemically activated deep electron traps in ntype InP by $\mathrm{Fe}$ implantation could be a powerful method to produce semi-insulating regions to be used as currentblocking layers in buried heterostructure lasers or heterojunction bipolar transistors.

The present work deals with the formation of good electrical isolation in Si-doped InP layers using $1 \mathrm{MeV}$ iron at different substrate temperatures. An annealing window is determined for effective electrical isolation. The effects exhibited by hot and cold implants are studied here in terms of the annealing characteristics of the sheet resistivity. The data for the evolution of sheet resistivity as a function of annealing temperature for iron-implanted $\mathrm{InP}$ layers maintained at $77 \mathrm{~K}, \mathrm{RT}, 100$ or $200^{\circ} \mathrm{C}$ is reported here for the first time.

\section{EXPERIMENTAL PROCEDURE}

Semi-insulating Fe-doped InP wafers of (100) orientation were used as substrates for the growth of n-type InP epilayers, with the (100) axis $2^{\circ}$ off normal orientation, using a Solid Source Molecular Beam Epitaxy reactor. An undoped InP buffer layer of thickness $1 \mu \mathrm{m}$ was first grown below the n-type layer. Silicon was used to dope the n-type layers with a concentration and thickness of $1 \times 10^{18} / \mathrm{cm}^{3}$ and $1 \mu \mathrm{m}$ respectively. The wafers were cleaved to obtain several samples of approximately $1 \mathrm{~cm}^{2}$ for the preparation of the resistors. All samples were cleaned in organic solvents and the clover-leaf pattern was printed on them using optical lithography. A solution of hydrochloric acid $(\mathrm{HCl})$ and phosphoric acid $\left(\mathrm{H}_{3} \mathrm{PO}_{4}\right)$ in the ratio of $1: 1$ by volume was used to etch the exposed area of n-type InP samples to a

*Fax : +44 1483534139, E-mail: p.too@eim.surrey.ac.uk 


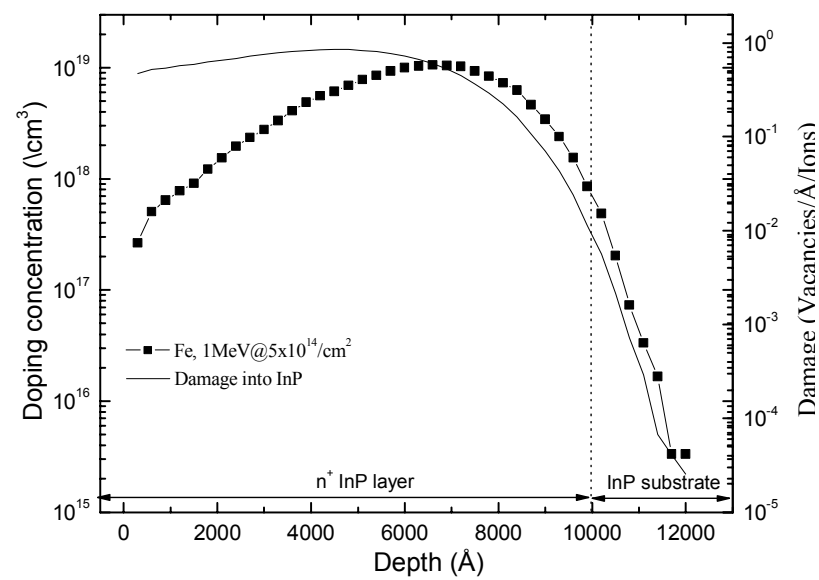

Figure 1. The relative position of the atomic distributions of the iron implant and the damage resulting from iron ions, as determined by TRIM.

depth of approximately $3 \mu \mathrm{m}$. The total etch depth was measured using a Rank Taylor Hobson Talystep, the error typically being $5 \%$. The photoresist was then removed in acetone leaving the cloverleaf Hall pattern on the samples.

The samples were divided into four different groups with implant isolation at temperatures of $77 \mathrm{~K}, 25^{\circ} \mathrm{C}, 100^{\circ} \mathrm{C}$, and $200^{\circ} \mathrm{C}$ using a $2 \mathrm{MV}$ High Voltage Engineering Europa (HVEE) implanter. The accuracy in the temperature control was $\pm 3^{\circ} \mathrm{C}$. During implantation, the sample was tilted about $7^{0}$ from the surface normal to minimize channeling. For $77 \mathrm{~K}$ implants, the samples were mounted on a cold stage, which was cooled using liquid nitrogen. The center of the Hall pattern for all the samples was irradiated with $\mathrm{Fe}^{+}$using a dose and energy of $5 \times 10^{14} \mathrm{~cm}^{-2}$ and $1 \mathrm{MeV}$ respectively, with a beam current density $<0.33 \mu \mathrm{A} / \mathrm{cm}^{2}$.

The post-implant annealing was performed in the range $100^{\circ} \mathrm{C}-800^{\circ} \mathrm{C}\left( \pm 5^{\circ} \mathrm{C}\right)$ for a time of $60 \mathrm{~s}$ in a nitrogen atmosphere, following a ramp up to a temperature of $60 \mathrm{~s}$. Samples were set in the face-to-face configuration with a whole two inch diameter virgin InP wafer covering the implanted sample surfaces. This provides a local phosphorous pressure to prevent dissociation of InP occurring near the surface during high temperature annealing $\left(>300^{\circ} \mathrm{C}\right)$. Ohmic contacts to the samples were fabricated by applying indium and sintering at approximately $200^{\circ} \mathrm{C}$ for $2 \mathrm{~min}$. Ohmic contacts were applied prior to isolation implants for those samples which required annealing below $200^{\circ} \mathrm{C}$.

The sheet resistivity, sheet carrier concentration and Hall mobility were measured using a Bio-Rad HL5500 Hall effect system employing Van der Pauw geometry at $300 \mathrm{~K}$ under a magnetic field strength of $0.32 \mathrm{~T}$. All measurements were done at RT for samples implanted at $77 \mathrm{~K}, 100^{\circ} \mathrm{C}$ and $200^{\circ} \mathrm{C}$.

\section{RESULTS AND DISCUSSION}

Figure 1 shows the range distribution and damage resulting from the iron implants into InP, as determined by

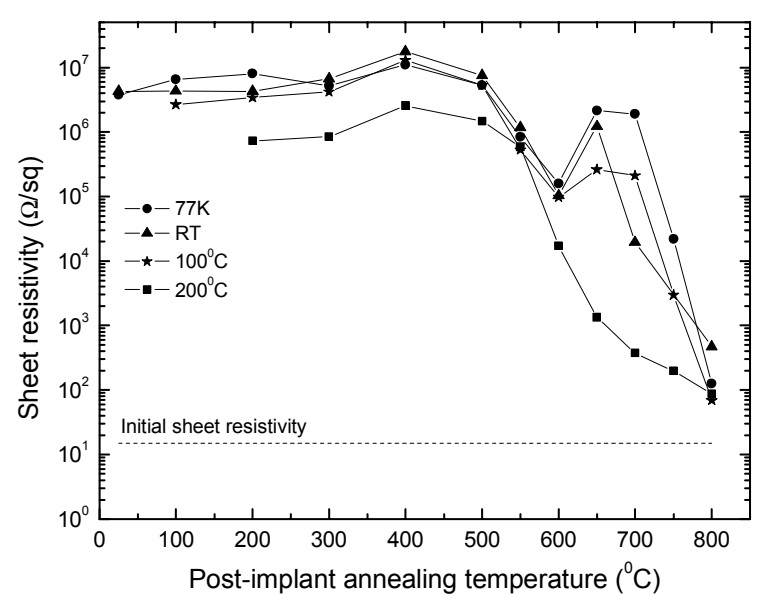

Figure 2. Evolution of sheet resistivity with different post-implant annealing temperature after rapid thermal annealing for $60 \mathrm{~s}$ in nitrogen atmosphere for iron implanted n-type InP layers irradiated with $5 \times 10^{14} \mathrm{~cm}^{-2}$ at $1 \mathrm{MeV}$ at $77 \mathrm{~K}, \mathrm{RT}, 100^{\circ} \mathrm{C}$ and $200^{\circ} \mathrm{C}$.

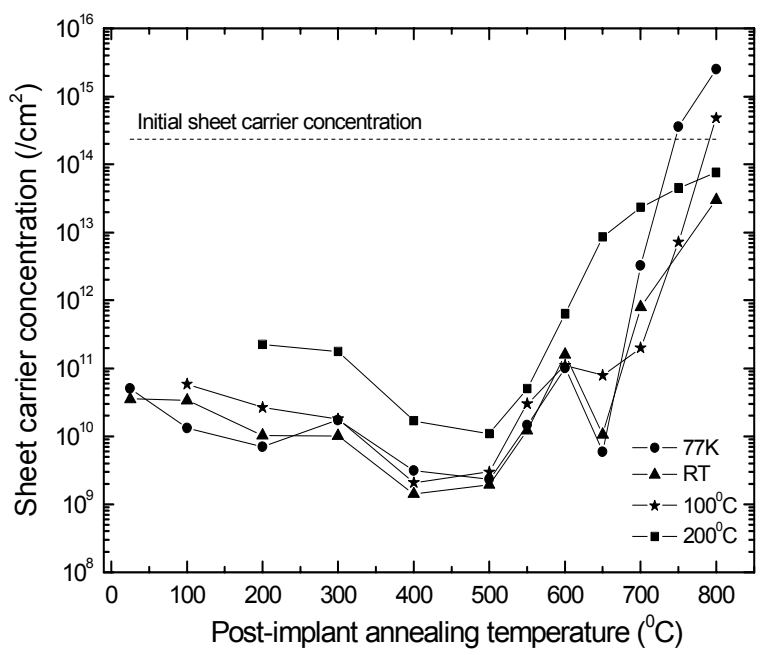

Figure 3. Variation of sheet carrier concentration with post-implant annealing temperature at $77 \mathrm{~K}, \mathrm{RT}, 100^{\circ} \mathrm{C}$ and $200^{\circ} \mathrm{C}$.

Transport of Ions in Matter (TRIM) [9]. The projected range of iron ions is approximately $0.6 \mu \mathrm{m}$ with a projected straggle of $0.20 \mu \mathrm{m}$, estimated by TRIM calculations. The energy of the iron beam was chosen to place most of the iron atoms well inside the doped region. In this way, the chemical compensation will be more effective for the electrical isolation of the n-type InP epilayer.

Figure 2 shows the evolution of sheet resistivity as a function of post-implant annealing temperature for layers isolated with $1 \mathrm{MeV}$ iron at $77 \mathrm{~K}, \mathrm{RT}, 100^{\circ} \mathrm{C}$ and $200^{\circ} \mathrm{C}$, respectively. The initial sheet resistivity of the n-type InP layer for all the samples is $\sim 15 \Omega / \square$. The initial mobility and sheet electron concentrations are $\sim 1775 \mathrm{~cm}^{2} /$ V.s and $2.3 \times 10^{14}$ $/ \mathrm{cm}^{2}$ respectively. After iron implantation, an as-implanted sheet resistivity of $\sim 5 \times 10^{6} \Omega / \square$ is obtained for substrate temperatures of $77 \mathrm{~K}$, RT, and $100^{\circ} \mathrm{C}$ and that of $200^{\circ} \mathrm{C}$ is $7 \times 10^{5} \Omega / \square$. Thus there is an increase in the sheet resistivity by almost five orders of magnitude and a decrease in sheet 
carrier concentration by four orders of magnitude (see figure 3). Most of the carriers are trapped at defect sites generated during the implantation causes the large increase in the sheet resistivity and this, together with a degradation in the mobility. A maximum resistivity of $\sim 1 \times 10^{7} \Omega / \square$ was obtained for $77 \mathrm{~K}$, RT and $100^{\circ} \mathrm{C}$ substrate temperatures after a postimplant annealing cycle of $400^{\circ} \mathrm{C}$ for $60 \mathrm{~s}$. After a similar anneal, a resistivity of $\sim 2 \times 10^{6} \Omega / \square$ was measured for the $200^{\circ} \mathrm{C}$ implant. Further increase in the post-annealing temperature above $400^{\circ} \mathrm{C}$ produces a decrease in sheet resistivity by at least one order of magnitude. However the sheet resistivity increases again at $650^{0} \mathrm{C}$ to $2.1 \times 10^{6}, 1.2 \times 10^{6}$ and $2.5 \times 10^{5} \Omega / \square$ for $77 \mathrm{~K}$, RT and $100^{\circ} \mathrm{C}$ implants respectively. This increase is not found for samples implanted at $200^{\circ} \mathrm{C}$. We infer that the isolation produced in our case is a product of both damage related centres and defects related to the presence of $\mathrm{Fe}$ at this annealing temperature.

A high sheet resistivity $\left(10^{6}-10^{7} \Omega / \square\right)$ is maintained until an annealing temperature of $500^{\circ} \mathrm{C}$ for all four substrate temperatures (see figure 2). This wide thermally stable annealing window is very useful from the technological point of view. Above $650^{\circ} \mathrm{C}$, there is a gradual decrease in sheet resistivity for all the substrate temperatures due to recovery of the carriers as the defects are annealed out. The out-diffusion of iron atoms towards the surface and deep into the bulk after annealing at $800^{\circ} \mathrm{C}$ is reported by Ridgway et al [10] using Secondary Ions Mass Spectroscopy which is in complete agreement with the interpretation of the decrease in the sheet resistivity above $650^{\circ} \mathrm{C}$.

We reported that for a high dose $\left(5 \times 10^{14} / \mathrm{cm}^{2}\right)$, the first few microns of an InP layer is amorphised for substrate temperature below $200^{\circ} \mathrm{C}$ [11]. However less damage is produced for $200^{\circ} \mathrm{C}$ implants due to enhanced dynamic annealing and this is most likely the reason why lower temperature implants produce higher resistivities. Most of the defects created at such an elevated temperature are annealed out during the implantation. Gasparotto et al [12] reported a similar phenomenon after $\mathrm{Fe}$ ion implantation in Sn doped $\mathrm{InP}$ at RT and $200^{\circ} \mathrm{C}$ using a dose and energy of $2 \times 10^{14} / \mathrm{cm}^{2}$ and $2 \mathrm{MeV}$ respectively. They used Rutherford backscattering spectroscopy (RBS) to show that less damage was created for high temperature implantation. RBS was also used by Bahir et al [13] to demonstrate that less damage was formed for $200^{\circ} \mathrm{C}$ implants of Si into SI InP using a fluence of $3.3 \times 10^{14}$ $/ \mathrm{cm}^{2}$ at $180 \mathrm{keV}$.

We infer that the increase in the sheet resistivity again at an annealing temperature of $650^{\circ} \mathrm{C}$ for samples implanted at $77 \mathrm{k}$, RT and $100^{\circ} \mathrm{C}$ is due to the chemical compensation effect of the iron atoms. This result agrees with that reported by Pearton et al [14]. He observed chemical compensation above an annealing temperature of $500^{\circ} \mathrm{C}$ for multiple $\mathrm{Fe}$ energies implantation into Sn-doped InP. He reported that the chemical compensation effect was present only when the $\mathrm{Fe}$ concentration was above that of the dopant, which is what we have shown from TRIM simulation. For a dose of $5 \times 10^{14}$ $/ \mathrm{cm}^{2}$, the $\mathrm{Fe}$ concentration is higher than the doping concentration by one order of magnitude.

\section{CONCLUSION}

In summary, we have assessed the behaviour of sheet resistivity and the thermal stability of the electrical isolation of n-type InP epilayers using iron implantation as a function of implant and annealing temperatures. A maximum sheet resistivity of $\sim 1 \times 10^{7} \Omega / \square$ is achieved for samples implanted at $77 \mathrm{~K}$, RT and $100^{\circ} \mathrm{C}$ after annealing at $400^{\circ} \mathrm{C}$. Implanting at $200^{\circ} \mathrm{C}$ produces lower resistivities, showing that there is no advantage in implanting at elevated temperatures. The semi-insulating properties of these epilayers are stable up to $500^{\circ} \mathrm{C}$ for all implantation temperatures. The single implant isolation scheme is inherently simple, has a wide thermally stable window and is compatible with conventional processing steps. These results demonstrate the potential usefulness of $\mathrm{Fe}$ implantation for device isolation application.

\section{ACKNOWLEDGMENT}

The authors gratefully acknowledge financial support from the UK Engineering and Physical Sciences Research Council (EPSRC). We also thank Mr. Adrian Cansell for performing the iron bombardments. We are grateful to the staff at the Sheffield III-V facility for the growth of the epilayers.

\section{REFERENCES}

[1] S. J. Pearton, "Ion-implantation in III-V semiconductor technology," Int. J. of Mod. Phys. B, vol. 7, no. 28, pp. 4687-4761, 1993.

[2] B. J. Sealy, and P. L. F. Hemment, "Ion beam techniques in microelectronics," Nucl. Inst. and Meth. $B$, vol. 89, pp. 298-306, 1994.

[3] M. C. Ridgway, R. G. Elliman, and N. Hauser, "MeV In-ion implantation for electrical isolation of $\mathrm{p}+-\mathrm{InP}$," Nucl. Inst. and Meth. B, vol. 80/81, pp. 835-837, 1993.

[4] H. Boudinov, H. H. Tan, and C. Jagadish, "Electrical isolation of n-type and p-type InP layers by proton bombardment," J. of Appl. Phys., vol. 89, no. 10, pp. 5343-5347, 2001.

[5] B. Tell, K. F. Brown-Goebeler, T. J. Bridges, and E. G. Burkhardt, "Resistance and mobility changes in InGaAs produced by light ion bombardment," J. of Appl. Phys., vol. 60 , no. 2, pp. 665-667, 1986.

[6] M. V. Rao, "Ion implantation in III-V compound semiconductors," Nucl. Inst. and Meth. B, vol. B79, pp. 645-647, 1993. 
[7] O. Mizuno, and H. Watanabe, "Semi-insulating properties of Fe-doped InP," Elec. Lett., vol. 11, pp.118119, 1975.

[8] M. V. Rao, "High-energy $(\mathrm{MeV})$ ion implantation and its device applications in GaAs and InP," IEEE Trans. on Elec. Dev., vol. 40, no. 6, pp.1053-1066, 1993.

[9] J. F. Ziegler, J. P. Biersack, and U. Littmark, The stopping and range of ions in solids. $1^{\text {st }}$ ed., Pergamon, Oxford, 1985.

[10] M. C. Ridgway, M. Davies, J. Z. Sedivy, R. Vandenberg, S. J. Rolfe, and T. E. Jackman, "MeV ion implantation for electrical isolation of $\mathrm{p}^{* *}$ plus InP epilayers," IEEE $5^{\text {th }}$ Intl. Conf. of Ind. Phos. and Rel. Mat., pp. 419-422, 1993.

[11] P.Too, S. Ahmed, B. J. Sealy, and R. Gwilliam, "Electrical isolation of n-type $\mathrm{InP}$ using $\mathrm{MeV}$ iron implantation at different doses and substrate temperatures," unpublished.

[12] A. Gasparotto, A. Carnera, C. Frigeri, F. Priolo, B. Fraboni, A. Camporese, and G. Rossetto, "Interaction between $\mathrm{Fe}$, dopants, and secondary defects in $\mathrm{MeV} \mathrm{Fe}$ ion implanted InP," J. Appl. Phys., vol. 85, no. 2, pp. 753-760, 1999.

[13] G. Bahir, J. L. Merz, J. R. Abelson, and T. W. Sigmon, "Iron redistribution and compensation mechanisms in semi-insulating Si-implanted InP," J. Appl. Phys. vol. 65, pp. 1009-1017, 1989.

[14] S. J. Pearton, C. R. Abernathy, M. B. Panish, R. A. Hamm, and L. M. Lunardi, "Implant induced highresistivity regions in InP and InGaAs," J. Appl. Phys. vol. 66, pp. 656-662, 1989. 